\title{
Polymerase chain reaction combined with fluorescent lateral flow immunoassay based on magnetic purification for rapid detection of canine parvovirus 2
}

\author{
Linlin Zhuang ${ }^{1}$, Yongxin $\mathrm{Ji}^{2}$, Peilong Tian ${ }^{1}$, Kaixuan Wang ${ }^{1}$, Chengkun $\mathrm{Kou}^{2}$, Ning Gu${ }^{1 *}$ and Yu Zhang ${ }^{1 *}$ (D)
}

\begin{abstract}
Background: Canine parvovirus 2 (CPV-2) is one of the most common etiological agents that cause severe gastroenteritis in puppies. Early accurate diagnosis is important for infected dogs. In recent years, magnetic separation has become an efficient and useful tool for bioassays. In this study, polymerase chain reaction (PCR) combined with fluorescent lateral flow immunoassay (LFIA) based on magnetic purification assay was developed for the quantitative detection of CPV-2.

Results: The optimum working reaction volume and reaction time for LFIA was $100 \mu \mathrm{L}$ and 2 min, respectively. The PCR-LFIA assay only detected CPV-2, and did not show cross-detection of non-CPV strains. Experiments showed analytical sensitivity of $3 \times 10^{1}$ copies/ML and demonstrated the PCR-LFIA has a diagnostic agreement of $100 \%$ with conventional PCR on detection of clinical samples (22.6\% positive, 14/62). Cutoff value is 146 . The results were further verified by sequencing and BLAST software. The entire process from PCR step only takes $\sim 80 \mathrm{~min}$.

Conclusions: This approach provides an attractive platform for rapid and quantitative detection of CPV-2, indicating great promise as a convenient molecular detection tool to facilitate disease outbreak investigations and response timely.
\end{abstract}

Keywords: Canine parvovirus, Polymerase chain reaction, Fluorescent lateral flow immunoassay, Magnetic purification

\section{Background}

Dogs as the most popular pets have spread globally, leaving a tremendous ecological paw print and market potentiality [1]. In the world wide, there is an increasing interest in keeping of dogs for various reasons hence it is necessary to prevent important fatal infectious diseases of dogs [2].

Canine parvovirus (CPV), a member of the Parvovirus genus, is one of the most common etiological agents that cause severe gastroenteritis in puppies of mainly 620 weeks old, especially unvaccinated puppies or those

\footnotetext{
* Correspondence: guning@seu.edu.cn; zhangyu@seu.edu.cn

'State Key Laboratory of Bioelectronics, Jiangsu Key Laboratory for Biomaterials and Devices, School of Biological Sciences and Medical Engineering and Collaborative Innovation Center of Suzhou Nano Science and Technology, Southeast University, No. 2, Sipailou, Xuanwu District, Nanjing, Jiangsu Province 210096, People's Republic of China

Full list of author information is available at the end of the article
}

with poor maternal protection through passive immunity $[3,4]$. Parvovirus replicates mainly in intestinal crypts and characterized by being highly contagious. CPV is a variant of the feline panleukopenia virus (FPV) with the new nomenclature of canine parvovirus type 2 (CPV-2) and differs genetically and antigenically from the canine minute virus, which designed as CPV-1 [5]. CPV-2 is responsible for hemorrhagic gastroenteritis with high rates of mortality and morbidity and became widespread since 1978 [6]. From the outbreak of CPV-2, three new antigenic variants were characterized and termed as CPV-2a, CPV-2b and CPV-2c [7]. However,the clinical diagnosis of CPV-2 infection is indecisive, since several other pathogens may cause diarrhoea in dogs [8]. Therefore, early accurate diagnosis of CPV-2 infection is quintessential, so that the infected dogs can receive

(c) The Author(s). 2019 Open Access This article is distributed under the terms of the Creative Commons Attribution 4.0 International License (http://creativecommons.org/licenses/by/4.0/), which permits unrestricted use, distribution, and reproduction in any medium, provided you give appropriate credit to the original author(s) and the source, provide a link to the Creative Commons license, and indicate if changes were made. The Creative Commons Public Domain Dedication waiver (http://creativecommons.org/publicdomain/zero/1.0/) applies to the data made available in this article, unless otherwise stated. 
timely and effective treatment to reduce morbidity and mortality.

Specific and sensitive laboratory diagnostic methods available for CPV detection have been developed over the years. Routinely, immunological-based methods such as enzyme-linked immunosorbent assay (ELISA), immunochromatographic (IC) and haemagglutination (HA) have been used to screen faeces from diarrhoeic dogs, but these methods are affected by relatively low sensitivity [9-11]. Virus isolation (VI) is more sensitive and accurate, while it is too time-consuming and laborious for pathogen detection [12]. With advances in molecular techniques, conventional and real-time PCR assays were gradually developed for $\mathrm{CPV}-2$ detection with higher sensitivity and specificity [13-15]. And further study showed that among above methods for detection of CPV-2, the best correlation was found between conventional and real-time PCR [8]. However, real-time PCR has not spread to the primary detection method due to its high equipment and reagent cost. Alternatively, conventional PCR assay based on agarose gel electrophoresis (PCR-GE), followed by nucleic acid dyes (such as ethidium bromide) staining, which poses a great potential threat to the health of the experimenter. All of these factors may have limited suitability for wide application.

To avoid gel electrophoresis and provide a portable, cost-effective platform to record results, PCR combined with lateral flow immunoassays (LFIAs), such as gold nanoparticle (AuNP)-based LFIAs, have been conducted [16-18]. PCR-LFIAs are convenient, quick and easy-operating. However, primer dimers and hairpins are known features in molecular diagnostic assays $[19,20]$. Due to the primer as a modified carrier, the dimer formed by the upstream and downstream primers also has the characteristic of PCR amplification products, which can also be recognized as a positive by the LFIA. To overcome the obstacles of false positive result, researchers have been exploring some effective ways to address primer dimers to increase the accuracy and specificity $[21,22]$. The probe method can reduce the effect of primer dimers, but it is still based on the principle of nucleic acid hybridization and difficult to solve the problem of primer (probe) dimers fundamentally. Furthermore, it not only adds the complexity of design and operation, but also increases inspection cost and time. On the other hand, the nucleic acid denaturant-based methods have great influence on DNA amplification products and the detection limit is affected. There is an urgent need in improved method for PCR products processing to higher accuracy.

In recent years, magnetic separation has become an interesting and useful tool for bioassays because the magnetic beads enable the isolation or extraction of target molecule or substance under the action of an external magnetic field [23, 24]. Due to the good biocompatibility and adequate functional groups for chemical fixation, magnetic beads modified with various recognition elements can be used for specific bioaffinity capture of different molecules. They are employed not only for magnetic separation of support from the reaction mixture but also as the solid adsorbent [25]. Therefore, magnetic beads have been applied to other areas such as immobilization of proteins and enzymes [26], bioseparation [27], immunoassay [28], drug delivery [29] and biosensors [30].

In this study, we describe the development and validation of a sensitive and specific PCR method combined with fluorescent lateral flow immunoassay (PCR-LFIA) based on magnetic beads purification for rapid detection of CPV-2 (Fig. 1). The LFIA used nanoparticles as signal amplifier, which ensures the sensitivity and accuracy to replace gel electrophoresis. With the LFIA reader Nanoeasy 1700, results can be quantified and shared in real time via the internet. The PCR-LFIA assay is rapid, sensitive, specific and safe, indicating great promise as a convenient tool to facilitate disease outbreak investigations and response timely.

\section{Methods}

\section{Virus strains and clinical samples}

Three canine parvovirus positive strains were isolated previously and confirmed by DNA sequencing (CPV-2-N1 strain, CPV-2a, GenBank accession number: MH660523; CPV-2-N2 strain, CPV-2b, GenBank accession number: MH660524; CPV-2-N3 strain, CPV-2c, GenBank accession number: MH660525) [3]. Several non-CPV strains, including pseudorabies virus (PRV, PRV-R1 strain, GenBank accession number: MH727488), canine distemper virus (CDV, CDV-NJ2 strain, GenBank accession number: MH727489), canine coronavirus (CCoV, CCoV-C5 strain, GenBank accession number: MH727490), canine parainfluenza virus (CPIV, CPIV-J2 strain, GenBank accession number: MH727491) were maintained in our laboratory.

Sixty-two nasal/oropharyngeal and faecal swabs were collected from 51 dogs of both sexes (various breeds and ages) from the animal hospital of Jubilancy, Nanjing and 11 dogs from the farms in Jiangsu Province, China during 2018 and snap-frozen for storage at $-80^{\circ} \mathrm{C}$. These swabs were collected from diarrheic dogs and nine of them were suspected for CPV infection. All samples were collected using sterile cotton swabs and were immersed immediately in screw capped polypropylene tubes containing sterile PBS of pH 7.2 [31].

\section{DNA/RNA extraction}

The swabs were squeezed and the liquid was extracted using the Magnetic Viral DNA Kit (Nanoeast, Nanjing, China) according to manufacturer's instructions. Viral RNA of non-CPV strains was extracted using Trizol 


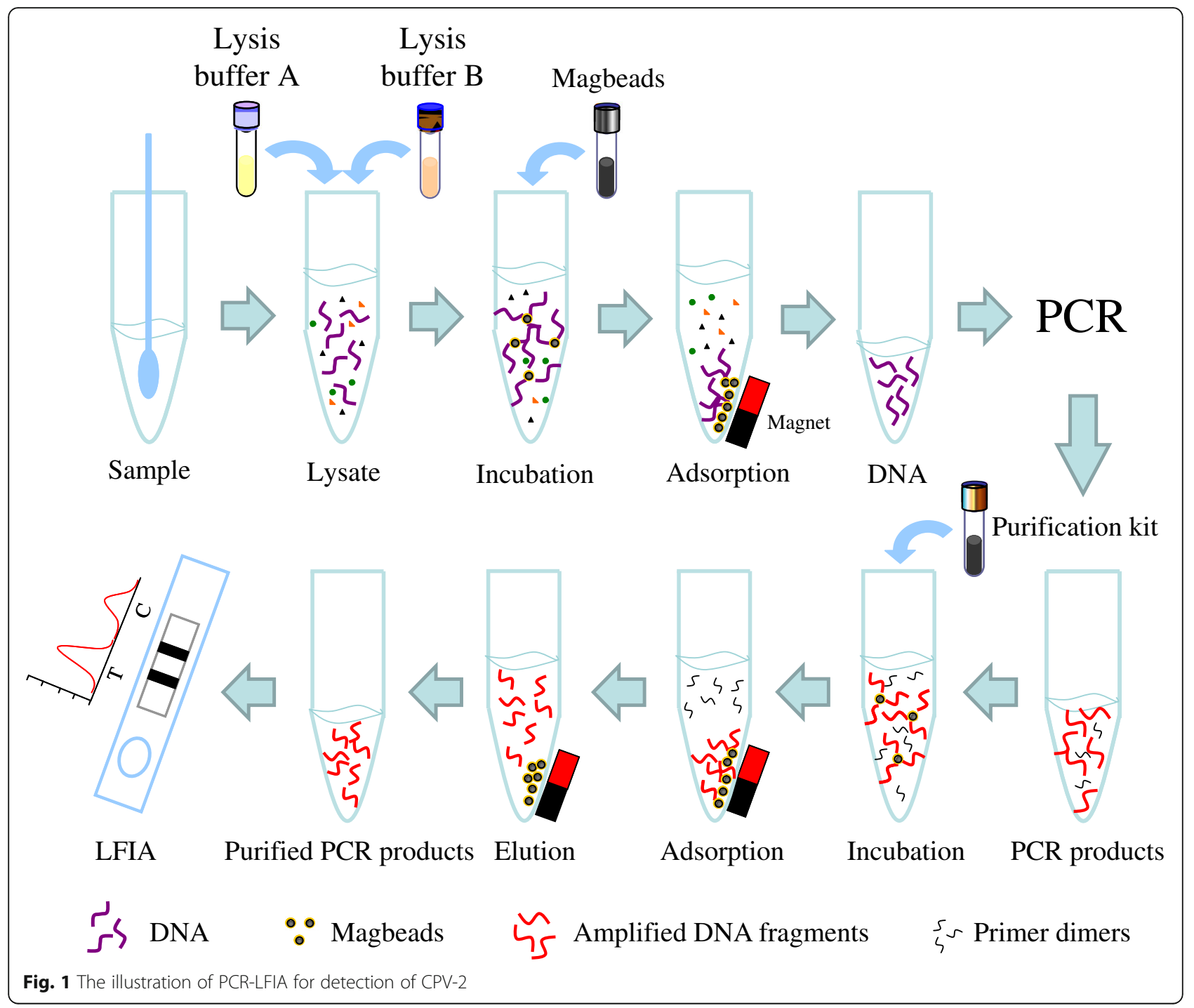

Reagent (TIANGEN, Beijing, China) according to manufacturer's instructions. The concentration of DNA templates was quantified by Nano-300 Micro Spectrophotometer (Allsheng, Hangzhou, China). All DNA/RNA templates were stored at $-80^{\circ} \mathrm{C}$ till further use.

\section{PCR conditions}

The polymerase chain reaction (PCR) primers were especially designed from consensus genome regions of VP2 gene according to previous study [32]. The biotin-labeled forward primer was 5'-Biotin-AATGTACCACCAGT TTATC-3' and the digoxigenin-labeled reverse primer was 5 '-digoxigenin-TGGGAGGCTCTTAGTTTAG-3'. The primers were assessed using NUPACK web software (http://www.nupack.org/) and their specificity was further verified by BLAST tool (http://blast.ncbi.nlm.nih.gov/Blast .cgi). The upstream and downstream primers are located in the conserved region of the VP2 gene and reasonably avoid the mutation sites [33]. Primers were synthesized by GENEWIZ (GENEWIZ, Suzhou, China).

Polymerase chain reaction was set up by adding $10 \mu \mathrm{L}$ Premix Taq $^{\text {Tм }}$ (TaKaRa Taq ${ }^{\text {TM }}$ Version 2.0) (TaKaRa, Dalian, China), $1 \mu \mathrm{L}$ PCR primers (10 $\mu \mathrm{M}$ each), $1 \mu \mathrm{L}$ DNA template and the reaction volume was made up to $20 \mu \mathrm{L}$ using nuclease free $\mathrm{ddH}_{2} \mathrm{O}$. PCR amplification was performed with an initial denaturation step of $94^{\circ} \mathrm{C}$ for 5 min, 35 cycles of denaturation at $94^{\circ} \mathrm{C}$ for $20 \mathrm{~s}$, annealing at $50{ }^{\circ} \mathrm{C}$ for $20 \mathrm{~s}$, and elongation at $72{ }^{\circ} \mathrm{C}$ for $20 \mathrm{~s}$, followed by a final extension step of $72{ }^{\circ} \mathrm{C}$ for $8 \mathrm{~min}$. PCR products were analyzed by $1.5 \%(w / v)$ agarose gel electrophoresis with DL-2000 DNA Marker (TaKaRa, Dalian, China) to estimate the fragment size of $253 \mathrm{bp}$. Finally, the PCR products were purified with Magbeads PCR Purification Kit (Nanoeast, Nanjing, China) for genomic sequencing (GenScript, Nanjing, China). And all CPV field strains detected in the clinical samples were 
characterised to assess the antigenic type according to previous report [33].

\section{PCR products purification and LFIA detection}

PCR products were purified by Magbeads PCR Purification Kit (Nanoeast, Nanjing, China). According to manufacturer's instructions, $5 \mu \mathrm{L}$ of amplified DNA was mixed with $10 \mu \mathrm{L}$ magbeads reagent (1:2). This ratio allows for optimal selection of PCR products with fragments length greater than $100 \mathrm{bp}$. The effect of PCR products purification was simultaneously verified by $1.5 \%(w / v)$ agarose gel electrophoresis and fluorescence lateral flow immunoassay (Nanoeast, Nanjing, China).

The final reaction volume for LFIA was optimized by adding the running buffer of $40 \mu \mathrm{L}, 60 \mu \mathrm{L}, 80 \mu \mathrm{L}, 100 \mu \mathrm{L}$ and $120 \mu \mathrm{L}$ to the sample tube containing about $20 \mu \mathrm{L}$ eluant, followed by mixing for $10 \mathrm{~s}$. Then, the mixed solution was added to the sampling window of the fluorescent lateral flow strip. The reaction time was optimized by incubating the mixture for $60 \mathrm{~s}, 90 \mathrm{~s}, 120 \mathrm{~s}, 150 \mathrm{~s}, 180$ $\mathrm{s}$ at room temperature. Finally, the images of test $(\mathrm{T})$ and control (C) lines were recorded by fluorescence imager (Nanoeast, Nanjing, China) and the related fluorescent signal values were read by LFIA reader Nanoeasy 1700 (Nanoeast, Nanjing, China).

\section{Specificity of the PCR-LFIA}

The specificity of the PCR-LFIA was established by testing three known positive strains (CPV-2-N1, CPV-2-N2, and CPV-2-N3) and several non-CPV strains (PRV-R1, CDV-NJ2, CCoV-C5, CPIV-J2) maintained in our laboratory. Previous study has verified the specificity of the PCR method based on its specific primers, the focus here is on verifying the specificity of PCR-LFIA [32]. Viral RNA was translated to cDNA by PrimeScript ${ }^{\text {ti }}$ RT Master Mix (TaKaRa, Dalian, China) before PCR. Each sample test was repeated three times.

\section{Sensitivity of the PCR-LFIA}

The genomic DNA of CPV-2-N1 strain was extracted for PCR amplification. PCR products were purified by Magbeads PCR Purification Kit (Nanoeast, Nanjing, China). The PCR amplification products were ligated into the pUC57 vector by using Hieff Clone ${ }^{\mathrm{Tx}}$ Zero TOPO-TA Cloning Kit (Yeasen, Shanghai, China) after purified and cloned in Escherichia coli. Positive clones were identified by sequencing (GenScript, Nanjing, China). The positive clones were cultured and the plasmids were extracted using Magnetic Plasmid Extraction Kit (Nanoeast, Nanjing, China), and the content of the plasmids was determined by Nano-300 Micro Spectrophotometer, then
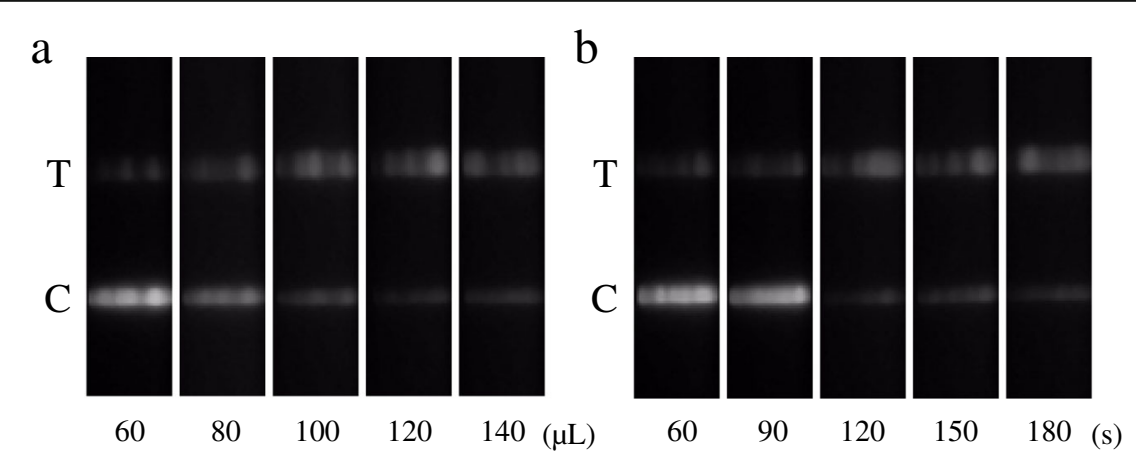

T 1362816375220582189221643

T 1473916631216592197522043

C $16351 \quad 15601 \quad 1126512673 \quad 12968$

C $19783 \quad 18262 \quad 1228513061 \quad 11506$
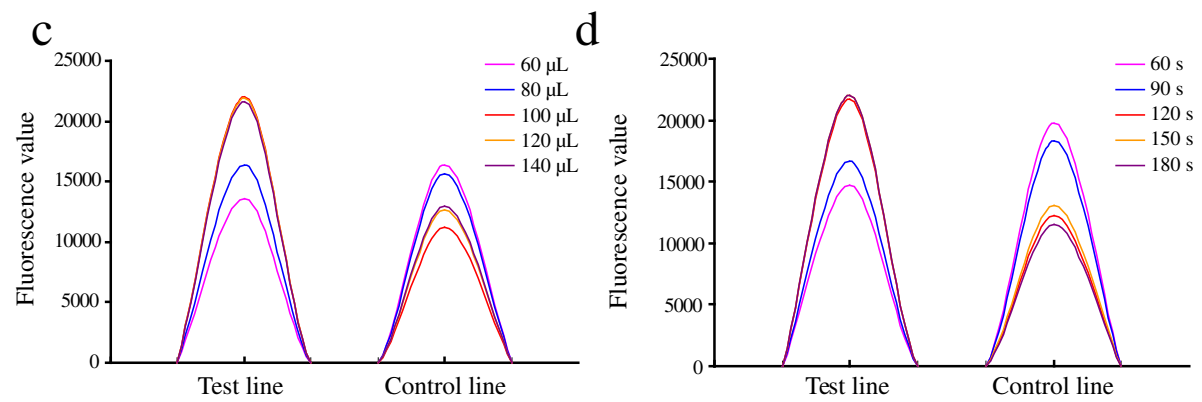

Fig. 2 Assay condition optimization for LFIA. a The working reaction solutions containing the purified PCR products (20 $\mu \mathrm{L})$ and running buffer with different volumes of $40 \mu \mathrm{L}, 60 \mu \mathrm{L}, 80 \mu \mathrm{L}, 100 \mu \mathrm{L}$ and $120 \mu \mathrm{L}$ was tested. b The reaction time was optimized by adding $100 \mu \mathrm{L}$ working reaction solution and incubating for $60 \mathrm{~s}, 90 \mathrm{~s}, 120 \mathrm{~s}, 150 \mathrm{~s}, 180 \mathrm{~s}$ at room temperature. The images of test (T) and control (C) lines were recorded by fluorescence imager. The fluorescence signals of test and control lines in $\mathbf{c}$ and $\mathbf{d}$ correspond to Fig. 2a and b, respectively 


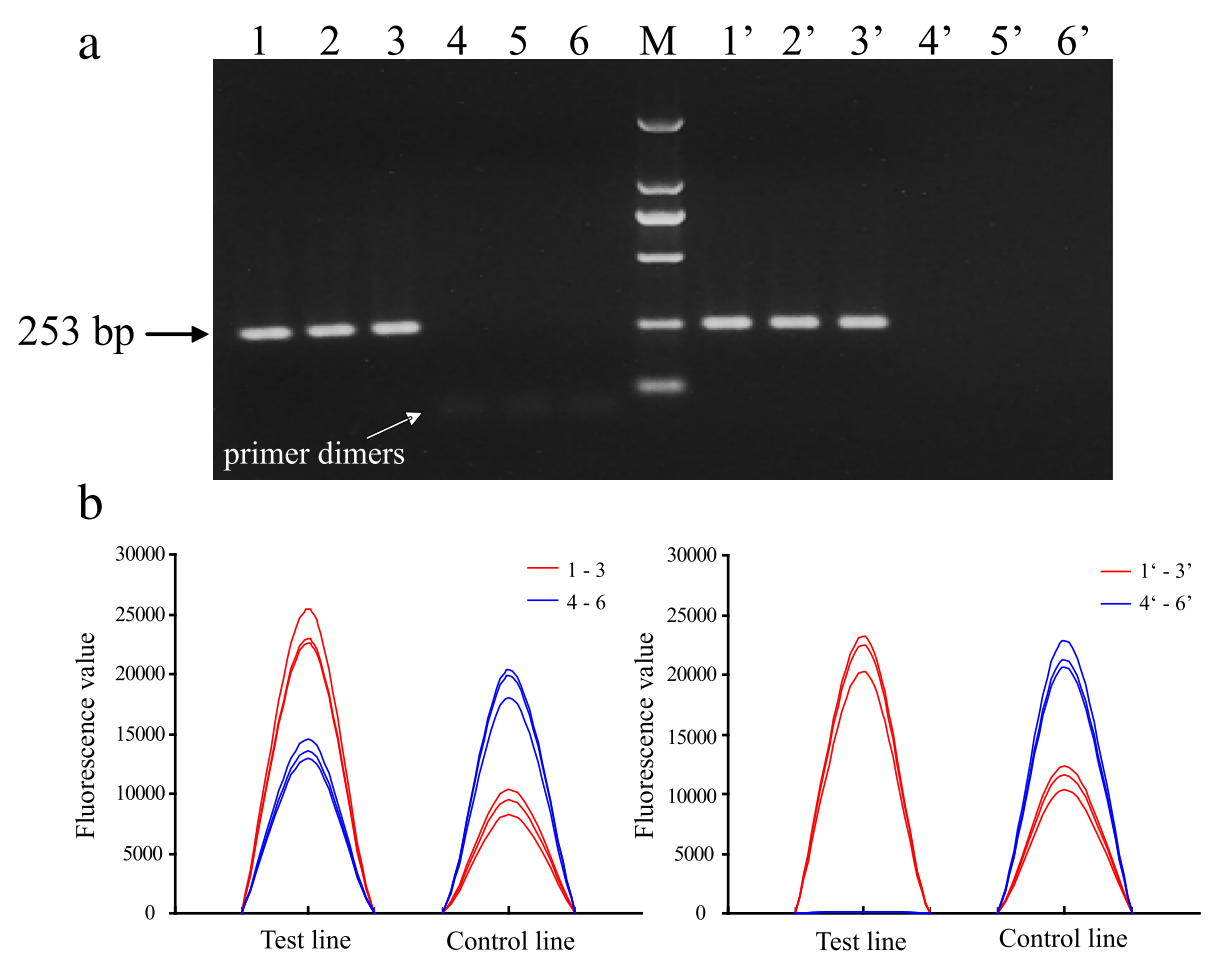

Fig. 3 The establishment of PCR-LFIA for CPV-2 detection. a PCR result determined by 1.5\% agarose gel electrophoresis. Lane M, DL-2000 DNA marker. Lane 1-3, positive control CPV-2-N1. Lane 4-6, negative control. Lane 1'-6', PCR products of positive and negative control purified by Magbeads PCR Purification Kit, respectively. b Corresponding fluorescence signals of test and control lines read by Nanoeasy 1700 for the same samples as in Fig. 3a

the plasmids were stored at $-20^{\circ} \mathrm{C}$. The plasmid copy number was calculated following the formula [34]: copies/ $\mu \mathrm{L}=\left(6.02 \times 10^{23}\right) \times\left(\mathrm{ng} / \mu \mathrm{L} \times 10^{-9}\right) /($ DNA length $\times 660)$ by using the plasmid pUC57 containing the desired fragment as a standard. Standard DNA is diluted from $3 \times 10^{8}$ to $3 \times 10^{0}$ copies $/ \mu \mathrm{L}$ for PCR amplification to evaluate the detection limit of PCR-LFIA.

\section{Results}

\section{Optimization of the LFIA}

Purified PCR products were tested using the LFIA to determine the optimal final reaction volume and time (Fig. 2). To achieve maximal fluorescence signal on test line, we optimized the working reaction volume in the range of $60 \mu \mathrm{L}-140 \mu \mathrm{L}$. As shown in Fig. 2, with the increasing of working reaction volume, the fluorescence signals reached the highest point in $100 \mu \mathrm{L}$ and maintained stably till $140 \mu \mathrm{L}$ (Fig. $2 \mathrm{a}$ and c). In addition, the fluorescence signals reached the highest point with incubating for $120 \mathrm{~s}$ at room temperature and slight difference in band clarity was observed with increasing reaction time from $120 \mathrm{~s}$ to $180 \mathrm{~s}$ (Fig. $2 \mathrm{~b}$ and d). The results showed that the best reaction condition was $100 \mu \mathrm{L}$ working reaction volume incubating for $120 \mathrm{~s}(2 \mathrm{~min})$ at room temperature, and thus was chosen for the following experiments.

\section{Establishment of PCR-LFIA for CPV-2 detection}

To establish the optimal conditions for PCR-LFIA, positive control (CPV-2-N1 strain) and negative control (PBS) were used for determining both amplified products and primer dimers and demonstrating the effect of PCR products purification (Fig. 3; Table 1). As shown in Fig. 3, the PCR-GE method confirmed a correct amplification target of 253-bp fragment. Only some primer dimers were observed in the negative control. In addition, the effect of PCR products purification was simultaneously verified by $1.5 \%$ agarose gel electrophoresis. The bands of positive control remained bright but the primer-dimer bands

Table 1 Fluorescence signal values of PCR products and purified PCR products measured by Nanoeasy 1700

\begin{tabular}{|c|c|c|c|c|c|}
\hline \multirow[t]{2}{*}{ Samples } & \multicolumn{2}{|c|}{ PCR products } & \multirow[t]{2}{*}{ Samples } & \multicolumn{2}{|c|}{ Purified PCR products } \\
\hline & $\bar{T}$ & C & & $\overline{\mathrm{T}}$ & $C$ \\
\hline 1 & 25,393 & 8237 & $1^{\prime}$ & 23,197 & 10,351 \\
\hline 2 & 23,016 & 9562 & $2^{\prime}$ & 22,459 & 11,623 \\
\hline 3 & 22,589 & 10,351 & $3^{\prime}$ & 20,264 & 12,362 \\
\hline 4 & 13,623 & 19,862 & $4^{\prime}$ & 102 & 21,292 \\
\hline 5 & 14,522 & 18,037 & $5^{\prime}$ & 118 & 20,634 \\
\hline 6 & 12,985 & 20,351 & $6^{\prime}$ & 95 & 22,835 \\
\hline
\end{tabular}





Fig. 4 Specificity assessment of the PCR-LFIA for CPV-2 detection. a Specificity of PCR assay performed by 1.5\% agarose gel electrophoresis. Lane M, DL-2000 DNA marker. Lane 1-8, CPV-2-N1, CPV-2-N2, CPV-2-N3, PRV-R1, CDV-NJ2, CCoV-C5, CPIV-J2, negative control, respectively. b Corresponding fluorescence signals of test and control lines for the same samples as in Fig. 4a

disappeared in negative control (Fig. 3a). Furthermore, the results of PCR-LFIA were then confirmed by Nanoeasy 1700. Correspondingly, the positive control displayed a specific characteristic peak of test line and showed a slight decrease with purification. However, the negative control showed no specific characteristic peak and its fluorescence value was significantly reduced with purification (below the test strip's cutoff value of 62) (Fig. 3b). The results verified the PCR method and the effect of purifying PCR products based on magnetic beads, which would effectively overcome the obstacle of false positive results.

\section{Specificity of PCR-LFIA for detection of CPV-2}

In order to evaluate the specificity of PCR-LFIA, potential cross-reactions were performed using DNA/RNA three positive strains (CPV-2-N1, CPV-2-N2, and CPV-2-N3) and several non-CPV strains (PRV-R1, CDV-NJ2, CCoV-C5, CPIV-J2) were tested in this study. PCR products were analyzed by $1.5 \%$ agarose gel electrophoresis and LFIA. As shown in Fig. 4a, cross-amplification tests using templates from PRV, CDV, CCoV and CPIV showed that no amplicons were detected, whereas the reaction using the CPV-2 template gave a positive result. The quantitative results were also obtained by Nanoeasy 1700

Table 2 Fluorescence signal values measured by Nanoeasy 1700

\begin{tabular}{lllllllll}
\hline & CPV-2-N1 & CPV-2-N2 & CPV-2-N3 & PRV-R1 & CDV-NJ2 & CCoV-C5 & CPIV-J2 $^{\text {NC* }}$ \\
\hline$T$ & 21,543 & 22,685 & 23,391 & 21 & 65 & 109 & 31 & 103 \\
$C$ & 10,359 & 9736 & 8702 & 19,063 & 18,055 & 20,165 & 18,341 & 19,352 \\
\hline
\end{tabular}

*NC indicates negative control 


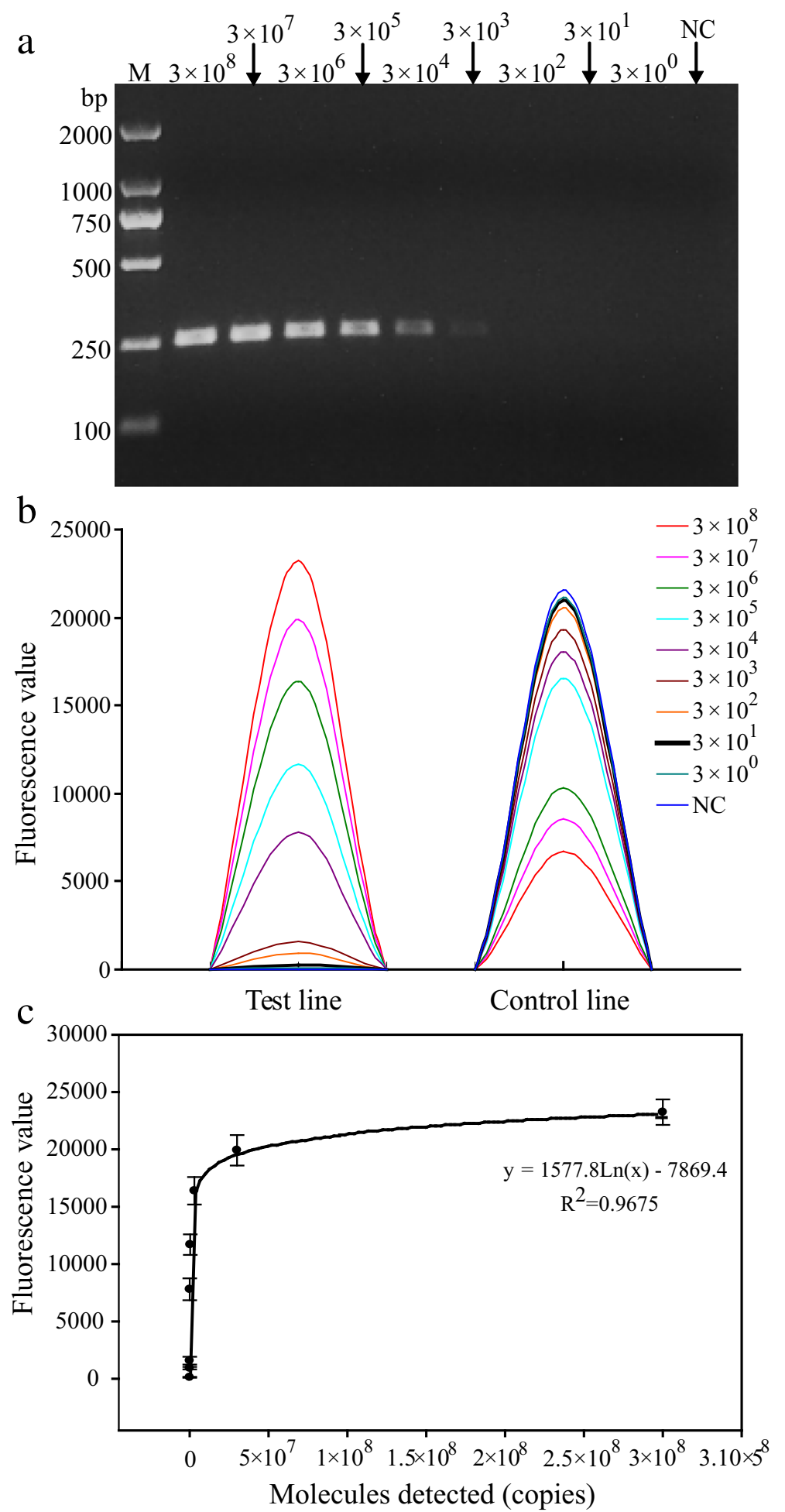

Fig. 5 Sensitivity comparison of PCR-GE and PCR-LFIA for the detection of CPV-2. a Sensitivity of PCR-GE performed by $1.5 \%$ agarose gel electrophoresis. Lane M, DL-2000 DNA marker. Lane $2-10,3 \times 10^{8}$ copies $/ \mu \mathrm{L}$ to $3 \times 10^{\circ}$ copies $/ \mu \mathrm{L}$ for standard DNA detected, respectively. Lane 11, negative control. b Corresponding signals of Test and Control lines for the same samples as in Fig. 5a. c Fluorescence signal values as a function of the copies of standard DNA detected. Each value was derived from three independent detections, and the error bars mean standard deviations 
Table 3 Fluorescence signal values as a function of the copies of standard DNA measured by Nanoeasy 1700

\begin{tabular}{lllllllllll}
\hline Copies & $3 \times 10^{8}$ & $3 \times 10^{7}$ & $3 \times 10^{6}$ & $3 \times 10^{5}$ & $3 \times 10^{4}$ & $3 \times 10^{3}$ & $3 \times 10^{2}$ & $3 \times 10^{1}$ & $3 \times 10^{0}$ & $\mathrm{NC}^{*}$ \\
\hline $\mathrm{T}_{1}$ & 23,256 & 21,439 & 17,285 & 12,643 & 6802 & 1878 & 1031 & 165 & 28 & 0 \\
$\mathrm{~T}_{2}$ & 22,138 & 18,948 & 16,859 & 10,853 & 8701 & 1206 & 929 & 93 & 66 \\
$\mathrm{~T}_{3}$ & 24,359 & 19,386 & 15,032 & 11,603 & 7902 & 1650 & 815 & 135 & 45 \\
$-\mathrm{X}$ & 23,251 & 19,924 & 16,392 & 11,700 & 7802 & 1578 & 925 & 131 & 46 & 11 \\
$\mathrm{SD}$ & 1111 & 1330 & 1197 & 899 & 953 & 342 & 108 & 37 & 19 \\
\hline
\end{tabular}

${ }^{*} \mathrm{NC}$ indicates negative control

(Table 2), and the specific characteristic peak appeared only for CPV-2 detection (Fig. 4b). These results indicated that the PCR-LFIA developed in this study was specific for CPV-2.

Sensitivity of PCR-LFIA and PCR-GE for detection of CPV-2 To determine the sensitivity of CPV-2 detection by PCR-GE and PCR-LFIA, the standard DNA stock $\left(3 \times 10^{8}\right.$ copies $\left./ \mu \mathrm{L}\right)$ was serially diluted tenfold. Each viral DNA $(1 \mu \mathrm{L})$ was used as a template for PCR where the respective dilutions were subjected to thermal cycling using the primer pair of biotin-labeled CPV-2-F and Digoxigenin-labeled CPV-2-R, which amplified a 253-bp fragment from the VP2 gene of CPV-2. In PCR-LFIA, standard DNA dilutions gave a fluorescence signal values ranging from 131 to 23,251 , and a linear relationship $\left(y=1577.8 \operatorname{Ln}(x)-7869.4, R^{2}=0.9675\right)$ was observed with CPV-2 titers decreasing from $3 \times 10^{8}$ to $3 \times$ $10^{0}$ copies $/ \mu \mathrm{L}$. The results showed that the sensitivity of PCR-LFIA for the detection of CPV-2 was $3 \times 10^{1}$ copies/ $\mu \mathrm{L}$, which was 100 times more sensitive than PCR-GE assay (Fig. 5; Table 3).

\section{PCR-LFIA for detection of CPV-2 in clinical samples}

Of the clinical samples, $22.6 \%$ (14 of 62) were determined to be CPV-2 positive by the PCR-LFIA. The cutoff value (the mean value plus $3 \times$ the standard deviation for negative samples) of LFIA is 146 (Fig. 6). The further analysis demonstrated the PCR-LFIA had a diagnostic agreement of $100 \%$ with PCR-GE (Table 4). All positive results were further confirmed by DNA sequencing to make sure that these are true positive isolates and there are no false-positive results. Sequences were edited using the SeqMan program and further verified by BLAST alignment tool (http://blast.ncbi.nlm.nih.gov/Blast.cgi). These sequences of CPV-2 isolated from other countries or regions such as USA, New Zealand, India, Singapore, Shanghai and Yangzhou (available through GenBank) were used for comparison with the fourteen CPV-2 isolates. Multiple-sequence alignments were constructed by

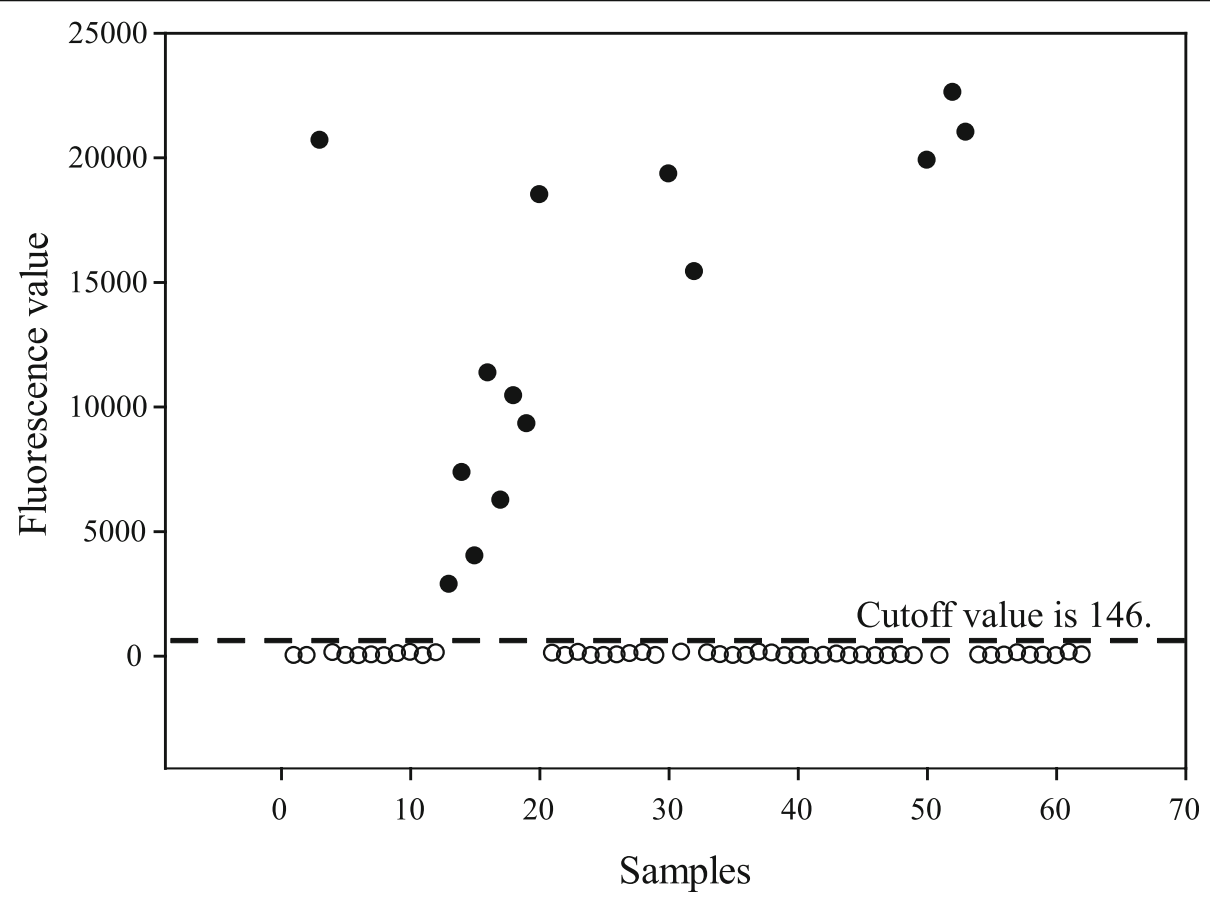

Fig. 6 Fluorescent signals of clinical samples detected by the PCR-LFIA. "•" and "o" indicates positive and negative results, respectively 
Table 4 Clinical sample information and test result comparison for PCR-GE, PCR-LFIA and DNA sequencing

\begin{tabular}{|c|c|c|c|c|c|c|c|c|c|c|}
\hline S. no. & Sample & $\begin{array}{l}\text { Age } \\
\text { (months) }\end{array}$ & Sex & Breed & $\begin{array}{l}\text { Clinical } \\
\text { suspicion }\end{array}$ & PCR-GE & PCR- LFIA & Signals & $\begin{array}{l}\text { Antigenic } \\
\text { type }\end{array}$ & $\begin{array}{l}\text { Accession } \\
\text { number }\end{array}$ \\
\hline 1 & SG-01 & 2 & $\mathrm{~F}$ & French Bulldog & - & - & - & 11 & & \\
\hline 2 & SG-02 & 3 & M & Pembroke Welsh Corgi & - & - & - & 5 & & \\
\hline 3 & NJ-0602-1 & 2.5 & $\mathrm{~F}$ & Border Collie & + & + & + & 20,685 & $2 c$ & MH614361 \\
\hline 4 & NJ-0602-2 & 3 & $\mathrm{~F}$ & Golden Retriever & - & - & - & 122 & & \\
\hline 5 & NJ-0602-3 & 12 & M & Pembroke Welsh Corgi & - & - & - & 9 & & \\
\hline 6 & NJ-0602-4 & 12.5 & $\mathrm{~F}$ & Shiba Inu & - & - & - & 0 & & \\
\hline 7 & NJ-0615-01 & 4 & M & Puppies & - & - & - & 32 & & \\
\hline 8 & NJ-0615-02 & 12 & $\mathrm{~F}$ & Pembroke Welsh Corgi & - & - & - & 0 & & \\
\hline 9 & NJ-0615-05 & 8 & M & Pembroke Welsh Corgi & - & - & - & 80 & & \\
\hline 10 & NJ-0615-06 & 2 & $\mathrm{~F}$ & Samoyed & - & - & - & 136 & & \\
\hline 11 & NJ-0615-10 & 2 & $\mathrm{~F}$ & Bichon Frise & - & - & - & 1 & & \\
\hline 12 & NJ-0615-11 & 2 & M & Teddy Bear & - & - & - & 121 & & \\
\hline 13 & NJ-0615-12 & 2.5 & $\mathrm{~F}$ & Golden Retriever & + & + & + & 2865 & $2 a$ & MH614362 \\
\hline 14 & NJ-0615-13 & 2 & $\mathrm{~F}$ & Pug & + & + & + & 7354 & $2 \mathrm{a}$ & MH614363 \\
\hline 15 & NJ-0615-14 & 2 & $\mathrm{~F}$ & Pug & + & + & + & 4003 & $2 c$ & MH614364 \\
\hline 16 & NJ-0622-1 & 1.5 & M & Pembroke Welsh Corgi & + & + & + & 11,345 & $2 c$ & MH614365 \\
\hline 17 & NJ-0622-2 & 3 & $\mathrm{~F}$ & French Bulldog & + & + & + & 6246 & $2 c$ & MH614366 \\
\hline 18 & NJ-0622-3 & 2.5 & M & Pembroke Welsh Corgi & + & + & + & 10,431 & $2 b$ & MH614367 \\
\hline 19 & NJ-0622-4 & 4 & $\mathrm{~F}$ & French Bulldog & + & + & + & 9311 & $2 c$ & MH614368 \\
\hline 20 & NJ-0622-5 & 4 & $\mathrm{~F}$ & Teddy Bear & + & + & + & 18,505 & $2 c$ & MH614369 \\
\hline 21 & NJ-0622-6 & 6 & M & Newfoundland and Labrador & - & - & - & 97 & & \\
\hline 22 & NJ-0622-7 & 8 & M & Bichon Frise & - & - & - & 10 & & \\
\hline 23 & NJ-0622-8 & 5 & $\mathrm{~F}$ & Bichon Frise & - & - & - & 132 & & \\
\hline 24 & NJ-0622-9 & 6 & $\mathrm{~F}$ & Shiba Inu & - & - & - & 5 & & \\
\hline 25 & NJ-0622-10 & 6 & $\mathrm{~F}$ & Alaskan Malamute & - & - & - & 10 & & \\
\hline 26 & NJ-0622-11 & 2 & M & Pomeranian & - & - & - & 31 & & \\
\hline 27 & NJ-0622-12 & 2 & M & Puppies & - & - & - & 82 & & \\
\hline 28 & NJ-0622-13 & 2.5 & $\mathrm{~F}$ & Pug & - & - & - & 128 & & \\
\hline 29 & NJ-0622-14 & 2 & $\mathrm{~F}$ & Teddy Bear & - & - & - & 12 & & \\
\hline 30 & NJ-0622-15 & 1.5 & M & Samoyed & - & + & + & 19,337 & $2 a$ & MH614370 \\
\hline 31 & NJ-0622-16 & 4 & $\mathrm{~F}$ & Bichon Frise & - & + & + & 138 & & \\
\hline 32 & NJ-0622-17 & 3 & M & Golden Retriever & - & + & + & 15,414 & $2 c$ & MH614371 \\
\hline 33 & NJ-0622-18 & 2 & $\mathrm{~F}$ & Pembroke Welsh Corgi & - & - & - & 116 & & \\
\hline 34 & NJ-0622-19 & 8 & M & Miniature Schnauzer & - & - & - & 41 & & \\
\hline 35 & NJ-0622-20 & 1.5 & $\mathrm{~F}$ & Pembroke Welsh Corgi & - & - & - & 7 & & \\
\hline 36 & NJ-0622-21 & 3 & $\mathrm{~F}$ & Border Collie & - & - & - & 10 & & \\
\hline 37 & NJ-0622-22 & 3 & M & Golden Retriever & - & - & - & 143 & & \\
\hline 38 & NJ-0622-23 & 3 & M & Golden Retriever & - & - & - & 105 & & \\
\hline 39 & NJ-0622-24 & 4 & $\mathrm{~F}$ & Pembroke Welsh Corgi & - & - & - & 0 & & \\
\hline 40 & NJ-0622-25 & 2.5 & M & Pembroke Welsh Corgi & - & - & - & 6 & & \\
\hline 41 & NJ-0622-26 & 2 & $\mathrm{~F}$ & French Bulldog & - & - & - & 3 & & \\
\hline 42 & NJ-0622-27 & 2 & M & Pembroke Welsh Corgi & - & - & - & 14 & & \\
\hline 43 & NJ-0622-28 & 3.5 & $\mathrm{~F}$ & French Bulldog & - & - & - & 70 & & \\
\hline
\end{tabular}


Table 4 Clinical sample information and test result comparison for PCR-GE, PCR-LFIA and DNA sequencing (Continued)

\begin{tabular}{|c|c|c|c|c|c|c|c|c|c|c|}
\hline S. no. & Sample & $\begin{array}{l}\text { Age } \\
\text { (months) }\end{array}$ & Sex & Breed & $\begin{array}{l}\text { Clinical } \\
\text { suspicion }\end{array}$ & PCR-GE & PCR- LFIA & Signals & $\begin{array}{l}\text { Antigenic } \\
\text { type }\end{array}$ & $\begin{array}{l}\text { Accession } \\
\text { number }\end{array}$ \\
\hline 44 & NJ-0622-29 & 4 & $\mathrm{~F}$ & Border Collie & - & - & - & 0 & & \\
\hline 45 & NJ-0622-30 & 5 & M & Samoyed & - & - & - & 23 & & \\
\hline 46 & NJ-0622-31 & 3 & M & Samoyed & - & - & - & 0 & & \\
\hline 47 & NJ-0622-32 & 2 & $\mathrm{~F}$ & Border Collie & - & - & - & 3 & & \\
\hline 48 & NJ-0622-33 & 2 & $\mathrm{~F}$ & Pug & - & - & - & 41 & & \\
\hline 49 & NJ-0622-34 & 2.5 & $\mathrm{~F}$ & Pug & - & - & - & 0 & & \\
\hline 50 & NJ-0622-35 & 1.5 & M & Pembroke Welsh Corgi & - & + & + & 19,881 & $2 c$ & MH614372 \\
\hline 51 & NJ-0622-36 & 2 & $\mathrm{~F}$ & Pug & - & - & - & 8 & & \\
\hline 52 & NJ-0622-37 & 2.5 & M & Pug & - & + & + & 22,607 & $2 a$ & MH614373 \\
\hline 53 & NJ-0622-38 & 3 & M & Pug & - & + & + & 21,010 & $2 c$ & MH614374 \\
\hline 54 & $X W-01$ & 5 & $\mathrm{~F}$ & Samoyed & - & - & - & 23 & & \\
\hline 55 & XW-02 & 4 & M & Samoyed & - & - & - & 9 & & \\
\hline 56 & $J C-01$ & 2.5 & $\mathrm{~F}$ & Teddy Bear & - & - & - & 25 & & \\
\hline 57 & $J C-02$ & 8 & M & Miniature Schnauzer & - & - & - & 113 & & \\
\hline 58 & JC-03 & 10 & M & Pembroke Welsh Corgi & - & - & - & 21 & & \\
\hline 59 & SG-0616 & 3.5 & $\mathrm{~F}$ & Golden Retriever & - & - & - & 19 & & \\
\hline 60 & SG-0618 & 2.5 & $\mathrm{~F}$ & Pug & - & - & - & 0 & & \\
\hline 61 & SG-0619 & 3 & M & Samoyed & - & - & - & 141 & & \\
\hline 62 & SG-0619 & 3 & M & Samoyed & - & - & - & 35 & & \\
\hline
\end{tabular}

using ClustalW method with the Lasergene MegAlign (DNASTAR, Madison, USA) software program (Fig. 7). All sequences of fourteen positive samples were submitted to National Center for Biotechnology Information databases (GenBank accession numbers: MH614361-MH614374).

\section{Discussion}

Parvovirus infections in dogs have become a global problem. The clinical signs resemble other enteric diseases and hence rapid and early diagnosis of the condition has become ever more urgent. Traditional methods such as virus isolation and electron microscopy are time-consuming, less sensitive, and expensive [35, 36]. Serological tests could detect the antibody, but fail to detect the acute infection. The commercial SNAP test is commonly used for rapid detection of CPV-2 on site, but it was less sensitive than PCR-based assays because it does not amplify the detection target during the test [7-9, 37]. Haemagglutination and immunochromatographic tests are widely used and simple, but they are less sensitive and always require fresh samples $[8,36]$. Hence, these tests are now replaced by molecular methods like PCR which has high specificity and sensitivity than the traditional methods [38, 39]. However, the necessity of expensive equipment and reagents (real-time PCR) or cumbersome electrophoresis equipment and condition (PCR-GE) restricts its wide application [40].
Being visual inspection not applicable, to provide a faster way to quantify the PCR results rather than gel electrophoresis, the first polymerase chain reaction combined with fluorescent lateral flow immunoassay (PCR-LFIA) based on magnetic beads for rapid detection of CPV-2 has been successfully developed in this study. The lateral flow immunoassay used nanoparticles as signal amplifier, which ensures the sensitivity and accuracy of this assay. The optimized PCR-LFIA only needs about 80 min from PCR step, which is faster than PCR-GE and free of expensive equipment and toxic reagents. Due to the PCR-LFIA does not need gel electrophoresis, it is time-saving and carcinogenic ethidium bromide does not have to be used. The PCR products can be easily detected by LFIA based on magnetic beads purification, which can reduce the total time for detection of CPV-2. Furthermore, the accuracy and specificity of the PCR-LFIA will be greatly improved because magnetic beads for PCR products purification are employed. It can effectively remove the pollution of oligonucleotides, primer dimers, salts and proteins in PCR products or enzymatic reaction solutions.

The PCR-LFIA and PCR-GE exhibit high detection efficiency, and the specificity and relevance of them were confirmed. The results obtained from this study revealed that the PCR-LFIA possesses a high specificity to CPV-2 by giving positive results for all tested isolates of CPV-2 while yielding a negative result for non-CPV strains. In 


\begin{tabular}{|c|c|c|c|c|c|c|c|c|c|c|c|c|c|c|c|c|c|c|c|c|c|c|c|}
\hline \multicolumn{23}{|c|}{ Percent Identity } & \multirow[b]{3}{*}{ AY742955 } \\
\hline \multirow{22}{*}{$\begin{array}{l}8 \\
0 \\
0 \\
0 \\
0 \\
0 \\
0 \\
0\end{array}$} & & 1 & 2 & 3 & 4 & 5 & 6 & 7 & 8 & 9 & 10 & 11 & 12 & 13 & 14 & 15 & 16 & 17 & 18 & 19 & 20 & & \\
\hline & 1 & & 99.2 & 99.2 & 100.0 & 99.2 & 99.2 & 99.2 & 99.2 & 99.2 & 99.2 & 99.2 & 99.6 & 98.8 & 99.2 & 99.2 & 99.6 & 99.6 & 99.2 & 99.2 & 99.2 & 1 & \\
\hline & 2 & 0.8 & & 100.0 & 99.2 & 100.0 & 100.0 & 100.0 & 100.0 & 100.0 & 100.0 & 100.0 & 99.6 & 99.6 & 100.0 & 100.0 & 99.6 & 99.6 & 100.0 & 100.0 & 100.0 & 2 & KP881640 \\
\hline & 3 & 0.8 & 0.0 & & 99.2 & 100.0 & 100.0 & 100.0 & 100.0 & 100.0 & 100.0 & 100.0 & 99.6 & 99.6 & 100.0 & 100.0 & 99.6 & 99.6 & 100.0 & 100.0 & 100.0 & 3 & KX469430 \\
\hline & 4 & 0.0 & 0.8 & 0.8 & & 99.2 & 99.2 & 99.2 & 99.2 & 99.2 & 99.2 & 99.2 & 99.6 & 98.8 & 99.2 & 99.2 & 99.6 & 99.6 & 99.2 & 99.2 & 99.2 & 4 & KY083103 \\
\hline & 5 & 0.8 & 0.0 & 0.0 & 0.8 & & 100.0 & 100.0 & 100.0 & 100.0 & 100.0 & 100.0 & 99.6 & 99.6 & 100.0 & 100.0 & 99.6 & 99.6 & 100.0 & 100.0 & 100.0 & 5 & KY922910 \\
\hline & 6 & 0.8 & 0.0 & 0.0 & 0.8 & 0.0 & & 100.0 & 100.0 & 100.0 & 100.0 & 100.0 & 99.6 & 99.6 & 100.0 & 100.0 & 99.6 & 99.6 & 100.0 & 100.0 & 100.0 & 6 & MF001435 \\
\hline & 7 & 0.8 & 0.0 & 0.0 & 0.8 & 0.0 & 0.0 & & 100.0 & 100.0 & 100.0 & 100.0 & 99.6 & 99.6 & 100.0 & 100.0 & 99.6 & 99.6 & 100.0 & 100.0 & 100.0 & 7 & NJ-0602-1 \\
\hline & 8 & 0.8 & 0.0 & 0.0 & 0.8 & 0.0 & 0.0 & 0.0 & & 100.0 & 100.0 & 100.0 & 99.6 & 99.6 & 100.0 & 100.0 & 99.6 & 99.6 & 100.0 & 100.0 & 100.0 & & NJ-0615-12 \\
\hline & 9 & 0.8 & 0.0 & 0.0 & 0.8 & 0.0 & 0.0 & 0.0 & 0.0 & & 100.0 & 100.0 & 99.6 & 99.6 & 100.0 & 100.0 & 99.6 & 99.6 & 100.0 & 100.0 & 100.0 & 9 & NJ-0615-13 \\
\hline & 10 & 0.8 & 0.0 & 0.0 & 0.8 & 0.0 & 0.0 & 0.0 & 0.0 & 0.0 & & 100.0 & 99.6 & 99.6 & 100.0 & 100.0 & 99.6 & 99.6 & 100.0 & 100.0 & 100.0 & 10 & NJ-0615-14 \\
\hline & 11 & 0.8 & 0.0 & 0.0 & 0.8 & 0.0 & 0.0 & 0.0 & 0.0 & 0.0 & 0.0 & & 99.6 & 99.6 & 100.0 & 100.0 & 99.6 & 99.6 & 100.0 & 100.0 & 100.0 & 11 & NJ-0622-1 \\
\hline & 12 & 0.4 & 0.4 & 0.4 & 0.4 & 0.4 & 0.4 & 0.4 & 0.4 & 0.4 & 0.4 & 0.4 & & 99.2 & 99.6 & 99.6 & 100.0 & 100.0 & 99.6 & 99.6 & 99.6 & 12 & NJ-0622-15 \\
\hline & 13 & 1.2 & 0.4 & 0.4 & 1.2 & 0.4 & 0.4 & 0.4 & 0.4 & 0.4 & 0.4 & 0.4 & 0.8 & & 99.6 & 99.6 & 99.2 & 99.2 & 99.6 & 99.6 & 99.6 & 13 & NJ-0622-17 \\
\hline & 14 & 0.8 & 0.0 & 0.0 & 0.8 & 0.0 & 0.0 & 0.0 & 0.0 & 0.0 & 0.0 & 0.0 & 0.4 & 0.4 & & 100.0 & 99.6 & 99.6 & 100.0 & 100.0 & 100.0 & & NJ-0622-2 \\
\hline & 15 & 0.8 & 0.0 & 0.0 & 0.8 & 0.0 & 0.0 & 0.0 & 0.0 & 0.0 & 0.0 & 0.0 & 0.4 & 0.4 & 0.0 & & 99.6 & 99.6 & 100.0 & 100.0 & 100.0 & 15 & NJ-0622-3 \\
\hline & 16 & 0.4 & 0.4 & 0.4 & 0.4 & 0.4 & 0.4 & 0.4 & 0.4 & 0.4 & 0.4 & 0.4 & 0.0 & 0.8 & 0.4 & 0.4 & & 100.0 & 99.6 & 99.6 & 99.6 & 16 & NJ-0622-35 \\
\hline & 17 & 0.4 & 0.4 & 0.4 & 0.4 & 0.4 & 0.4 & 0.4 & 0.4 & 0.4 & 0.4 & 0.4 & 0.0 & 0.8 & 0.4 & 0.4 & 0.0 & & 99.6 & 99.6 & 99.6 & 17 & NJ-0622-37 \\
\hline & 18 & 0.8 & 0.0 & 0.0 & 0.8 & 0.0 & 0.0 & 0.0 & 0.0 & 0.0 & 0.0 & 0.0 & 0.4 & 0.4 & 0.0 & 0.0 & 0.4 & 0.4 & & 100.0 & 100.0 & 18 & NJ-0622-38 \\
\hline & 19 & 0.8 & 0.0 & 0.0 & 0.8 & 0.0 & 0.0 & 0.0 & 0.0 & 0.0 & 0.0 & 0.0 & 0.4 & 0.4 & 0.0 & 0.0 & 0.4 & 0.4 & 0.0 & & 100.0 & 19 & NJ-0622-4 \\
\hline & 20 & 0.8 & 0.0 & 0.0 & 0.8 & 0.0 & 0.0 & 0.0 & 0.0 & 0.0 & 0.0 & 0.0 & 0.4 & 0.4 & 0.0 & 0.0 & 0.4 & 0.4 & 0.0 & 0.0 & & 20 & NJ-0622-5 \\
\hline & & 1 & 2 & 3 & 4 & 5 & 6 & 7 & 8 & 9 & 10 & 11 & 12 & 13 & 14 & 15 & 16 & 17 & 18 & 19 & 20 & & \\
\hline
\end{tabular}

Fig. 7 Identity and divergence analysis of partial VP2 gene in CPV-2 isolates. The partial VP2 nucleotide sequences from fourteen CPV-2 isolates were sequenced and analyzed by using ClustalW method with the Lasergene MegAlign software program for percent identity and divergence. The percent sequence identity was between $99.2 \% \sim 100 \%$

the same reaction conditions, PCR-LFIA showed 100 times more sensitive than PCR-GE when 10-fold serial dilutions of standard DNA were used. The sensitivity of PCR-LFIA with standard DNA in this study was $3 \times 10^{1}$ copies $/ \mu \mathrm{L}$. The sensitivity was also higher than conventional PCR and recombinase polymerase amplification assay [41, 42]. The verification result of PCR-LFIA showed a similar sensitivity to the previously reported qPCR and real-time recombinase polymerase amplification assay $[15,43]$, while the inexpensive equipment required for PCR-LFIA makes the latest valuable molecular test method, especially for resource limited setting. The PCR-LFIA saves the time required for detection, and is safe and reliable. With the LFIA reader Nanoeasy 1700, the results can be quantified and shared in real time via the internet, making it convenient for customers to communicate with doctors.

\section{Conclusion}

In conclusion, the first quantitative fluorescent PCRLFIA assay for CPV-2 detection was successfully established. It had the high sensitivity of $3 \times 10^{1}$ copies $/ \mu \mathrm{L}$. Cutoff value is 146 . The developed PCR-LFIA is a sensitive, rapid, simple and valuable tool for quantitative detection of CPV-2 for both research and diagnostic purposes. It can also serve as a suitable molecular detection tool to facilitate timely and effective pathogenic microorganism investigations and response.

\section{Abbreviations}

AuNP: Gold nanoparticle; C: Control line; CCoV: Canine coronavirus; CDV: Canine distemper virus; CPIV: Canine parainfluenza virus; CPV: Canine parvovirus; CPV-2: Canine parvovirus 2; ELISA: Enzyme-linked immunosorbent assay; FPV: Feline panleukopenia virus; HA: Haemagglutination:

IC: Immunochromatographic; LFIA: Lateral flow immunoassay; PBS: Phosphate buffer saline; PCR: Polymerase chain reaction; PCR-GE: Polymerase chain reaction based on agarose gel electrophoresis; PRV: Pseudorabies virus; qPCR: Quantitative polymerase chain reaction; T: Test line; VI: Virus isolation; VP2: Capsid protein

\section{Acknowledgements}

We thank Jiexia Cao at the Nanjing Nanoeast Biotech Co., Ltd. for valuable comments.

\section{Funding}

This work was supported by the National Key Research and Development Program of China (No. 2017YFA0205502), National Natural Science Foundation of China (No. 61821002, 81571806, 81671820), the Science and Technology Support Project of Jiangsu Province (No. BE2017763), and the Fundamental Research Funds for the Central Universities. The funders had no role in study design, in the collection, analysis and interpretation of data, in the writing the manuscript, or in the decision to submit the article for publication.

\section{Availability of data and materials}

The dataset analyzed during the current study is available from the corresponding author on reasonable request. 


\section{Authors' contributions}

LLZ, YXJ, NG, YZ designed and conducted the experiment. LLZ, YXJ, PLT, $\mathrm{KXW}$, and CKK performed the experiments and analyzed the data. LLZ drafted the manuscript. All authors read, revised, and approved the final manuscript.

\section{Ethics approval and consent to participate}

The animal protocol was approved by the Science and Technology Department of Jiangsu Province and Animal Care Ethics Committee of Southeast University (Nanjing, Jiangsu Province, People's Republic of China) [Approval No. SYXK (Su) 2016-0014]. Permissions were obtained from the veterinary clinics and the pet dog farm owners.

\section{Consent for publication}

Not applicable.

\section{Competing interests}

The authors declare that they have no competing interests.

\section{Publisher's Note}

Springer Nature remains neutral with regard to jurisdictional claims in published maps and institutional affiliations.

\author{
Author details \\ 'State Key Laboratory of Bioelectronics, Jiangsu Key Laboratory for \\ Biomaterials and Devices, School of Biological Sciences and Medica \\ Engineering and Collaborative Innovation Center of Suzhou Nano Science \\ and Technology, Southeast University, No. 2, Sipailou, Xuanwu District, \\ Nanjing, Jiangsu Province 210096, People's Republic of China. ${ }^{2}$ Nanjing \\ Nanoeast Biotech Co., Ltd., Nanjing, Jiangsu 210009, People's Republic of \\ China.
}

Received: 17 October 2018 Accepted: 3 January 2019

Published online: 17 January 2019

\section{References}

1. Treves A, Bonacic C. Humanity's dual response to dogs and wolves. Trends Ecol Evol. 2016;31(7):489-91.

2. Souza JM, Zappa V. Canine parvovirus. J Sci. Vet Med. 2008;6(11):4

3. De la Torre D, Mafla E, Puga B, Erazo L, Astolfi-Ferreira C, Ferreira AP. Molecular characterization of canine parvovirus variants (CPV-2a, CPV-2b, and (PV-2C) based on the VP2 gene in affected domestic dogs in Ecuador. Vet World. 2018;11(4):480-7.

4. Figueire do J, Miranda C, Souto R, Silva E, Fafetine J, Thompson G. Genetic characterization of canine parvovirus type 2 subtypes in Maputo, Mozambique. Arch Microbiol. 2017;199(4):543-9.

5. Cotmore SF, Agbandje-McKenna M, Chiorini JA, Mukha DV, Pintel DJ, Qiu J, Soderlund-Venermo M, Tattersall P, Tijssen P, Gatherer D, Davison AJ. The family Parvoviridae. Arch Virol. 2014;159(5):1239-47.

6. Denzengrini R, Weiblen R, Flores EF. Seroprevalence of parvovirus, adenovirus, coronavirus and canine distemper virus infections in dogs of Santa Maria, Rio Grande do Sul, Brazil. Ciência Rural. 2007:37(1):183-9.

7. Sun YL, Yen CH, Tu CF. Visual detection of canine parvovirus based on loopmediated isothermal amplification combined with enzyme-linked immunosorbent assay and with lateral flow dipstick. J Vet Med Sci. 2014; 76(4):509-16.

8. Desario C, Decaro N, Campolo M, Cavalli A, Cirone F, Elia G, Martella V Lorusso E, Camero M, Buonavoglia C. Canine parvovirus infection: which diagnostic test for virus? J Virol Methods. 2005;126(1-2):179-85.

9. Uwatoko K, Sunairi M, Nakajima M, Yamaura K. Rapid method utilizing the polymerase chain reaction for detection of canine parvovirus in feces of diarrheic dogs. Vet Microbiol. 1995;43(4):315-23.

10. Esfandiari J, Klingeborn B. A comparative study of a new rapid and one-step test for the detection of parvovirus in faeces from dogs, cats and mink. J Vet Med B Infect Dis Vet Public Health. 2000;47(2):145-53.

11. Castro TX, Uchoa CMA, Albuquerque MC, Labarthe NV, RdCNC G. Canine parvovirus (CPV-2) and intestinal parasites: laboratorial diagnosis and clinical signs from puppies with gastroenteritis. Int J Appl Res Vet Med. 2007;5(2): 72-6.

12. Mochizuki M, San Gabriel MV, Nakatani H, Yoshida M, Harasawa R. Comparison of polymerase chain reaction with virus isolation, haemagglutination assays for the detection of canine parvoviruses in faecal specimens. Res Vet Sci. 1993;55(1):60-3.

13. Buonavoglia C, Martella V, Pratelli A, Tempesta M, Cavalli A, Buonavoglia D, Bozzo G, Elia G, Decaro N, Carmichael L. Evidence for evolution of canine parvovirus type-2 in Italy. J Gen Virol. 2001;82(Pt 12):3021-5.

14. Kaur G, Chandra M, Dwivedi PN, Narang D. Multiplex real-time PCR for identification of canine parvovirus antigenic types. J Virol Methods. 2016; 233:1-5.

15. Sun Y, Cheng Y, Lin P, Yi L, Tong M, Cao Z, Wang G, Li S, Cheng S, Yuan W, Wang J. A multiplex TaqMan real-time PCR for detection and differentiation of four antigenic types of canine parvovirus in China. Mol Cell Probes. 2018; 38:7-12.

16. Foord AJ, Middleton D, Heine HG. Hendra virus detection using loopmediated isothermal amplification. J Virol Methods. 2012;181(1):93-6.

17. Yang Y, Li Q, Wang S, Chen X, Du A. Rapid and sensitive detection of Babesia bovis and Babesia bigemina by loop-mediated isothermal amplification combined with a lateral flow dipstick. Vet Parasitol. 2016;219: $71-6$

18. Cheng N, Song Y, Zeinhom MMA, Chang YC, Sheng L, Li H, Du D, Li L, Zhu MJ, Luo Y, Xu W, Lin Y. Nanozyme-mediated dual immunoassay integrated with smartphone for use in simultaneous detection of pathogens. ACS Appl Mater Interfaces. 2017;9(46):40671-80.

19. Kalendar $R$, Lee $D$, Schulman $A H$. FastPCR software for $P C R$, in silico PCR and oligonucleotide assembly and analysis. Methods Mol Biol. 2014;1116: 271-302.

20. Meagher RJ, Priye A, Light YK, Huang C, Wang E. Impact of primer dimers and self-amplifying hairpins on reverse transcription loop-mediated isothermal amplification detection of viral RNA. Analyst. 2018;143(8):192433.

21. Mamba TS, Mbae CK, Kinyua J, Mulinge E, Mburugu GN, Njiru ZK. Lateral flow loop-mediated isothermal amplification test with stem primers: detection of Cryptosporidium species in Kenyan children presenting with diarrhea. J Trop Med. 2018;2018:7659730.

22. Lalle M, Possenti A, Dubey JP, Pozio E. Loop-mediated isothermal amplification-lateral-flow immunoassay (LAMP-LFD) to detect Toxoplasma gondii oocyst in ready-to-eat salad. Food Microbiol. 2018;70:137-42.

23. Chen WJ, Tsai PJ, Chen YC. Functional nanoparticle-based proteomic strategies for characterization of pathogenic bacteria. Anal Chem. 2008; 80(24):9612-21.

24. Ravindranath SP, Mauer LJ, Deb-Roy C, Irudayaraj J. Biofunctionalized magnetic nanoparticle integrated mid-infrared pathogen sensor for food matrixes. Anal Chem. 2009;81(8):2840-6.

25. Taylor JI, Hurst CD, Davies MJ, Sachsinger N, Bruce IJ. Application of magnetite and silica-magnetite composites to the isolation of genomic DNA. J Chromatogr A. 2000;890(1):159-66.

26. Hromadkova L, Kupcik R, Vajrychova M, Prikryl P, Charvatova A, Jankovicova B, Ripova D, Bilkova Z, Slovakova M. Kinase-loaded magnetic beads for sequential in vitro phosphorylation of peptides and proteins. Analyst. 2018; 143(2):466-74.

27. Xu H, Aguilar ZP, Yang L, Kuang M, Duan H, Xiong Y, Wei $H$, Wang A. Antibody conjugated magnetic iron oxide nanoparticles for cancer cell separation in fresh whole blood. Biomaterials. 2011;32(36):9758-65.

28. Yang Y, Xu F, Xu H, Aguilar ZP, Niu R, Yuan Y, Sun J, You X, Lai W, Xiong Y, Wan C, Wei H. Magnetic nano-beads based separation combined with propidium monoazide treatment and multiplex PCR assay for simultaneous detection of viable Salmonella typhimurium, Escherichia coli 0157:H7 and Listeria monocytogenes in food products. Food Microbiol. 2013;34(2):418-24.

29. Wang FQ, Li P, Zhang JP, Wang AQ, Wei Q. pH-sensitive magnetic alginatechitosan beads for albendazole delivery. Pharm Dev Technol. 2011;16(3): 228-36.

30. Geng $P$, Zhang $X$, Teng $Y, F u Y, X u L, X u$ M, Jin L, Zhang W. A DNA sequence-specific electrochemical biosensor based on alginic acid-coated cobalt magnetic beads for the detection of E. coli. Biosens Bioelectron. 2011 26(7):3325-30.

31. Tinky SS, Ambily R, Nair SR, Mini M. Utility of a rapid immunochromatographic strip test in detecting canine parvovirus infection compared with polymerase chain reaction. Vet World. 2015;8(4):523-6.

32. Liu C, Pang C, Liu C, Wang J, Liu Q, Liang L, Yuan W, Qian A, Cui S. Establishment and rudimentary application of the multiplex PCR (MPCR) to the detection of CDV CPV-2, CAV-2 and CPIV China Anim Health Inspection. 2017;34(11):89-93. 
33. Behera M, Panda SK, Das S, Sahoo PK, Acharya AP, Patra RC, Pati S. Genomic typing and phylogenetic analysis of canine parvovirus detected in the state of Odisha. India Veterinarski Arhiv. 2016;86(5):727-41.

34. Yun JJ, Heisler LE, Hwang II, Wilkins O, Lau SK, Hyrcza M, Jayabalasingham B, Jin J, McLaurin J, Tsao MS, Der SD. Genomic DNA functions as a universal external standard in quantitative real-time PCR. Nucleic Acids Res. 2006; 34(12):e85.

35. Cho HS, Kang J, Park NY. Detection of canine parvovirus in fecal samples using loop-mediated isothermal amplification. J Vet Diagn Investig. 2006; 18(1):81-4.

36. Silva MMO, Castro TX, Costa EM, Trancoso TAL, Mendes-de-Almeida F, Labarthe NV, Garcia RCNC. Comparison of three laboratorial tests for diagnosis of canine parvovirus infection. Arq Bras Med Vet Zootec. 2013; 65(1):149-52.

37. Wang J, Liu L, Li R, Wang J, Fu Q, Yuan W. Rapid and sensitive detection of canine parvovirus type 2 by recombinase polymerase amplification. Arch Virol. 2016;161(4):1015-8.

38. Subhashini CR, Meerarani S, Ramadass P, Nachimuthu K. Polymerase chain reaction and latex agglutination test for detection of canine parvovirus infection. Indian J Virol. 1997;13(1):65-8.

39. Sakulwira K, Oraveerakul K, Poovorawan Y. Detection and genotyping of canine parvovirus in enteritic dogs by PCR and RFLP. Sci Asian. 2001;27:143-7.

40. Mohyedini SH, Jamshidi SH, Rafati S, Nikbakht GHR, Malmasi A, Taslimi Y, Akbarein $\mathrm{H}$. Comparison of immunochromatographic rapid test with molecular method in diagnosis of canine parvovirus. Iran J Vet Med. 2013; 7(1):57-61.

41. Deng X, Zhang J, Su J, Liu H, Cong Y, Zhang L, Zhang K, Shi N, Lu R, Yan X. A multiplex PCR method for the simultaneous detection of three viruses associated with canine viral enteric infections. Arch Virol. 2018;163(8):2133-8.

42. Liu L, Wang J, Geng Y, Wang J, Li R, Shi R, Yuan W. Equipment-free recombinase polymerase amplification assay using body heat for visual and rapid point-of-need detection of canine parvovirus 2. Mol Cell Probes. 2018; $39: 41-6$.

43. Geng Y, Wang J, Liu L, Lu Y, Tan K, Chang YZ. Development of real-time recombinase polymerase amplification assay for rapid and sensitive detection of canine parvovirus 2. BMC Vet Res. 2017;13(1):311.

Ready to submit your research? Choose BMC and benefit from:

- fast, convenient online submission

- thorough peer review by experienced researchers in your field

- rapid publication on acceptance

- support for research data, including large and complex data types

- gold Open Access which fosters wider collaboration and increased citations

- maximum visibility for your research: over $100 \mathrm{M}$ website views per year

At $\mathrm{BMC}$, research is always in progress.

Learn more biomedcentral.com/submissions 